\title{
Semantic, syntactic, and phonological processing of written words in adult developmental dyslexic readers: an event-related brain potential study
}

\author{
Jascha Rüsseler ${ }^{1}$, Petra Becker ${ }^{1}$, Sönke Johannes ${ }^{2}$ and Thomas F Münte*1
}

Address: ${ }^{1}$ Department of Psychology II, Neuropsychology Unit, Otto-von-Guericke University Magdeburg, Germany and ${ }^{2}$ Reha-Klinik Bellikon, Switzerland

Email: Jascha Rüsseler - jascha.ruesseler@nat.uni-magdeburg.de; Petra Becker - Thorsten.Becker@t-online.de;

Sönke Johannes - soenke.johannes@rehabellikon.ch; Thomas F Münte* - thomas.muente@med.uni-magdeburg.de

* Corresponding author

Published: 17 July 2007

BMC Neuroscience 2007, 8:52 doi:10.1 I86/147|-2202-8-52

This article is available from: http://www.biomedcentral.com/147I-2202/8/52

(c) 2007 Rüsseler et al; licensee BioMed Central Ltd.

This is an Open Access article distributed under the terms of the Creative Commons Attribution License (http://creativecommons.org/licenses/by/2.0), which permits unrestricted use, distribution, and reproduction in any medium, provided the original work is properly cited.
Received: 22 February 2007

Accepted: 17 July 2007

\begin{abstract}
Background: The present study used event-related brain potentials to investigate semantic, phonological and syntactic processes in adult German dyslexic and normal readers in a word reading task. Pairs of German words were presented one word at a time. Subjects had to perform a semantic judgment task (house - window; are they semantically related?), a rhyme judgment task (house - mouse; do they rhyme?) and a gender judgment task (das - Haus [the - house]; is the gender correct? [in German, house has a neutral gender: das Haus]).

Results: Normal readers responded faster compared to dyslexic readers in all three tasks. Onset latencies of the $\mathrm{N} 400$ component were delayed in dyslexic readers in the rhyme judgment and in the gender judgment task, but not in the semantic judgment task. N400 and the anterior negativity peak amplitudes did not differ between the two groups. However, the N400 persisted longer in the dyslexic group in the rhyme judgment and in the semantic judgment tasks.

Conclusion: These findings indicate that dyslexics are phonologically impaired (delayed N400 in the rhyme judgment task) but that they also have difficulties in other, non-phonological aspects of reading (longer response times, longer persistence of the N400). Specifically, semantic and syntactic integration seem to require more effort for dyslexic readers and take longer irrespective of the reading task that has to be performed.
\end{abstract}

\section{Background}

Developmental dyslexia is characterized by a difficulty in written language processing in persons possessing the intelligence and motivation considered necessary for accurate and fluent reading. More formally, it has been defined as a specific developmental impairment in the ability to read and spell despite adequate educational resources, average non-verbal intelligence, no obvious sensory deficits and appropriate socio-cultural opportunities $[1,2]$. Dyslexia occurs in all languages and is perhaps the most common developmental learning disorder affecting children with prevalence rates ranging from $5 \%$ to $17.5 \%$ [3-6]. Both, prospective and retrospective longitudinal studies indicate that dyslexia is a chronic, persistent condition $[7,8]$ and, thus, does not represent a developmental lag [9]. Over time, poor and good readers 
tend to maintain their relative positions along the spectrum of reading ability. However, adult dyslexic readers have problems that differ from those of dyslexic children. Their main problems are poor spelling, slow reading, decoding, and nonword-reading [10-12].

Most researchers agree that developmental dyslexia is a disorder of neurobiological origin. Family history is one important risk factor: 23 to 65 percent of children with a dyslexic parent are also dyslexic [13]. Independent research groups identified gene-loci on chromosomes 2 , 6 , and 15 that appear to be linked to dyslexia [for reviews, see [14-17]], whereas loci on chromosomes 1, 3, and 18 have been reported by single research groups only [18]. The exact relationship between biological and cognitive factors causing the disorder is still under debate, however [for one recent proposal, see [19]]. Theories proposed to explain developmental dyslexia include the visual theory [20], the rapid auditory processing theory [21-23], the cerebellar theory [24], the magnocellular theory [25] and the phonological theory [2,26-29].

A great number of behavioral and event-related brain potential (ERP) studies have been aimed at seeking evidence for these theories and thus have used rather simple stimuli [e.g. [30-40]]. The question to what extent different aspects of language processing are impaired has been addressed to a much lesser extent. Therefore, the present study investigates the processing of visually presented pairs of words by means of ERPs in three different conditions: a phonological or rhyme judgment task (RJT), a semantic judgment task (SJT), and a syntactic judgment task (GJT; gender judgment task).

ERPs can be used to study language processing [for reviews, see $[41,42]]$ because different components have been found to be sensitive to semantic and syntactic aspects of language processing. For example, the N400 component of the ERP is a negative peak usually occurring approximately $400 \mathrm{~ms}$ post-stimulus. It is generally reduced for visually or auditorily presented words that are semantically primed, i.e. for target words that are preceded by a related word, or that are part of a semantically congruous sentence ([43]; for a review, see [42]). The prevailing interpretation of the N400 is that its amplitude varies as a function of the ease with which a word can be integrated into the overall meaning representation that is built up on the basis of the preceding language input, be it a sentence or a single word [44-48]. In line with this interpretation, N400-amplitude has been found to be influenced by phonological information as well [49-51]. As an example, Rugg [52,53] observed that when the second of two visually presented words rhymed with the first, the N400 for the second word was reduced compared to a non-rhyming word. The scalp distribution of this N400- effect for rhyming words is similar to that of the semantic priming effect. Typically, the N400 has a broad scalp distribution with a slight lateralization to the right and a maximum at centro-parietal locations [54,55].

Syntactic violations have been reported to elicit negativities that differ in timing and scalp distribution from those observed for semantic incongruencies $(55,56]$. These negativities usually show a more frontal maximum compared to the N400 and are sometimes larger over the left hemisphere, although in many studies bilateral distributions have been observed [e.g. [45]]. They occur within the same time-range as the N400 (i.e. 300 to $500 \mathrm{~ms}$ after stimulus presentation) [57].

ERP-studies of semantic and phonological processing in dyslexic readers have yielded mixed results. Some authors reported delayed, reduced or absent N400 word priming effects for adult [58-60] and adolescent dyslexics [61,62]. These findings were interpreted as reflecting problems in the engagement of long-term semantic memory. These deficits have been found to vary as a function of presentation rate (pronounced N400 differences only at slow presentation rates in a word-by-word sentence reading task) [63], word frequency (more pronounced N400 amplitude reduction for low frequency words) [58], mode of stimulus presentation (visual or auditory), and subtype of reading disability (phonetic dyslexics do not show a normal N400 priming effect for auditorily presented words, but dysphonetic dyslexics do) [61]. In contrast, Bonte and Blomert (2004), Silva-Pereyra et al. (2003), and Rüsseler et al. (2003) [64-66] observed normal N400 priming effects in dyslexic and poor reading children and adults, respectively.

Syntactic processing in dyslexia has not often been the subject of investigation with ERPs, and all of the studies to date have employed sentence reading tasks. Leikin [67] found higher amplitudes and longer latencies for the P200, P300 and P600 in dyslexic readers that were interpreted as suggesting the existence of a syntactic processing weakness in dyslexic readers. Rispens [68] obtained no differences between normal and dyslexic readers in the ELAN, an early, left frontal negativity reflecting a highly automatised processing phase of syntactic parsing [69]. As in the aforementioned studies of Leikin and coworkers, the P600 was changed in dyslexics, but only for some forms of grammatical violations. A recent study by Sabisch and co-workers [70] presented phrase structure violations in passive sentences to dyslexic children and controls. While control children showed an early starting bilaterally distributed anterior negativity and a late centro-parietal positivity (P600), dyslexics ERPs were characterized by a delayed left lateralized anterior negativity, followed by a P600. The authors concluded that early 
automatic phrase structure building processes, which are reflected in the anterior negativity, are delayed in dyslexic children. Furthermore, the bilateral distribution of the early effect in controls was taken to suggest an involvement of prosodic processes localized in the right hemisphere in addition to the left hemispheric syntactic processes. The left-lateralized negativity in dyslexic on the other hand was interpreted in the sense of phonological impairment in dyslexic children (i.e. no right hemisphere contribution) which might lead to an impariment of syntactic processes. Thus, there is evidence for syntactic processing difficulties in dyslexic readers, but the exact nature of the problems is still a matter of debate.

The heterogenity of the findings in ERP-research on semantic, phonological, and syntactic processing in dyslexia can be attributed to several factors. First, different tasks have been used (word recognition; picture-wordpriming; sentence reading; visual or auditory stimulus presentation). Second, dyslexics taking part in the above mentioned studies differed with respect to age and level of reading impairment. Finally, semantic, phonological and syntactic processing have not been studied in the same sample of dyslexics outside of the sentence context. Thus, in the present study, semantic, phonological and syntactic processing was investigated in a same sample of adult normal and dyslexic readers. To this purpose, we used the presentation of word pairs rather than sentences.

As stated earlier, three word reading tasks were employed. In the RJT, subjects had to decide whether the second of two consecutively presented words rhymed with the first. In the SJT, participants had to judge whether the second word was semantically related to the first whereas in the GJT, it had to be decided whether the gender of the critical word matched that indicated by the first word. ERPs were computed relative to the presentation of the second word of the consecutively presented word pairs.

We decided to include only high-achieving dyslexic readers (university students) in our sample to minimize the chances of studying individuals with another comorbid developmental disorder, such as specific language impairment (SLI), ADHD or developmental coordination disorder [for a similar approach, see [71]]. Thus, any deficit in language processing found in the present study can be viewed as a "core deficit" of developmental dyslexia.
Because of the well-known difficulties in phonological processing in dyslexia [2,26-29], we expected a delay of ERP effects in the RJT. To the extent that these difficulties might propagate to later processing stages (see, for example, [70]), a delay in the ERP effects to gender and semantic violations was also expected.

\section{Results \\ Behavioral data}

The reaction times (RTs) and percentage of correct responses for the three tasks are shown in Table 1. There were main effects of GROUP $(\mathrm{F}(1,20)=27.41$, p < $.00001)$ and TASK $(\mathrm{F}(2,40)=16.31, \mathrm{p}<.00001)$ reflecting the fact that RTs were fastest in the rhyme judgment task and that normal readers responded faster than dyslexics. No significant interaction between factors GROUP and TASK was obtained. Statistical analysis of the accuracy data revealed the same pattern as the RT analysis indicating that no speed-accuracy trade-off was present for one of the groups.

\section{Event-related brain potentials RJT}

For the first $200 \mathrm{~ms}$ the ERPs to congruent and incongruent words are almost identical. However, beginning approximately $250 \mathrm{~ms}$ after the onset of the word the ERPs to incongruent, non-rhyming words display a more negative-going waveform (see Fig. 1). This effect is most prominent at central and parietal electrode locations and slightly larger for right hemisphere sites (see topographic isovoltage maps derived from the difference waves, figure 1 , rightmost column). The incongruency effect is reflected by the difference waves (figure 1, third column) for normal and dyslexic readers. Obviously, the N400 starts and peaks earlier in normal compared to dyslexic readers. By contrast, the N400 persists much longer in dyslexics. Statistically, this is reflected in an earlier N400 onset latency for normal compared to dyslexic readers (one-sided t-test against 0: control $240 \mathrm{~ms}$, dyslexics: $272 \mathrm{~ms}$; measured at electrode C4) and an earlier N400 peak latency (401 ms vs. $493 \mathrm{~ms}, \mathrm{~F}(1,20)=7.14, \mathrm{p}=.0146$, measured at $\mathrm{C} 4)$.

Due to the different N400 peak latencies, amplitude differences between normal and dyslexic readers were analyzed using the $\mathrm{N} 400$ peak amplitude values. The negative maximum for each subject was determined in a time-window ranging from $200-700 \mathrm{~ms}$. In contrast to the visual

Table I: Behavioral data

\begin{tabular}{|c|c|c|c|c|c|c|}
\hline & \multicolumn{3}{|c|}{ RT (ms) } & \multicolumn{3}{|c|}{$\%$ correct responses } \\
\hline & RJT & SJT & GJT & RJT & SJT & GJT \\
\hline Controls & II03 (4I.8) & $1273(37.4)$ & $1229(34.1)$ & $97.7(0.55)$ & $96.1(0.5 \mathrm{I})$ & $89.1(2.42)$ \\
\hline Dyslexics & $1327(64.2)$ & $1568(62.7)$ & $159 \mid(60.1)$ & $93.4(2.01)$ & $90.7(2.85)$ & $84.6(3.64)$ \\
\hline
\end{tabular}

Reacton times and percentage of correct responses (s.e.m.) for normal and dyslexic readers in the three tasks. 

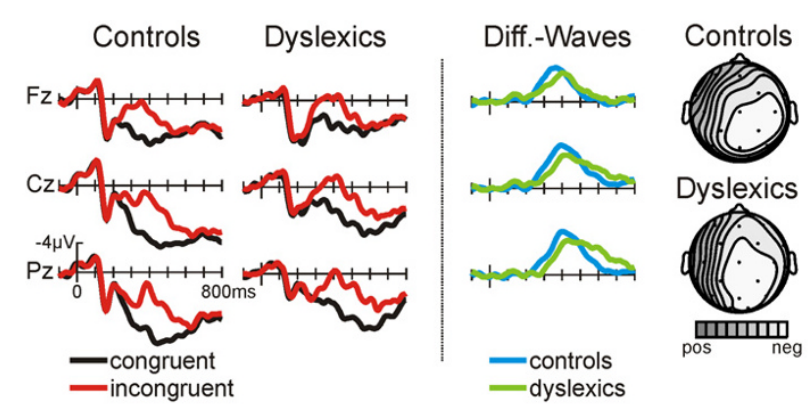

Figure I

ERPs in the RJT. ERPs in the rhyme judgment task for the control groups (left) and for dyslexic readers (middle). The right column depicts the difference waves (incongruent congruent) for the control group (solid line) and for the dyslexic readers (dotted line). Voltage and time scales of the left column pertain to all columns. Distributions are illustrated for the maximum of the difference waves as spline-interpolated isovoltage maps (relative scaling, controls $\mathrm{min} / \mathrm{max}-5.9$ / $-0.4 \mu \mathrm{V}$, dyslexics $-4.8 / 0.2 \mu \mathrm{V}$ ).

impression (Fig. 1, third columns), no significant N400 amplitude difference between the groups emerged at any electrode. The analysis of the differences waves yielded the same pattern of results.

The incongruency effect (larger negativity for non-rhymes compared to rhymes) turned out to be highly significant for both, dyslexic and normal readers (see Table 2).

\section{SJT}

For the first $200 \mathrm{~ms}$ the ERPs to words following semantically congruent primes and to words following incongruent primes are virtually identical. However, beginning approximately $250 \mathrm{~ms}$ after the onset of the word, the
ERPs to incongruent words display a more negative-going waveform (see Fig. 2, columns 1 and 2). This effect is most prominent at central and parietal electrode locations and again is slightly larger for right hemisphere sites (see topographic isovoltage maps in figure 2). The incongruent congruent difference waves (figure 2, third column) suggest that the N400 has the same onset latency for normal and dyslexic readers but that it is more extended in time in the dyslexic group. Indeed, N400-onset-latency does not differ between dyslexic and normal readers (one-sided t-test against 0: control $272 \mathrm{~ms}$, dyslexics: $272 \mathrm{~ms}$; measured at electrode C4). However, while the N400 amplitude seems to be larger in the dyslexic group no significant group differences were obtained for the mean amplitude in the 500 to $650 \mathrm{~ms}$ and 650 to $800 \mathrm{~ms}$ time windows (all $\mathrm{p}<.20$ ). In addition, no GROUP by ANTERIORITY or GROUP by LATERALITY interactions were seen. Again, the incongruency effect (larger N400 amplitude for incongruent words) turned out to be highly significant for both groups (see Table 2).

An analysis of the mean amplitude values of the difference waves at electrode P4 revealed a strong tendency for the N400 to persist longer in dyslexics compared to the controls (main effect GROUP, $500-800 \mathrm{~ms}, \mathrm{~F}(1,20)=3.55$, $\mathrm{p}<.074)$.

\section{GJT}

For the first $400 \mathrm{~ms}$ the ERPs to syntactically correct words and to syntactically incorrect words show a very similar waveform. However, beginning at approximately $400 \mathrm{~ms}$ the ERPs to grammatically incorrect words (with respect to the preceding article) display a more negative going waveform (see Fig. 3). This effect is most prominent at central and right temporal electrode locations as is evident in the topographic isovoltage maps (figure 3, rightmost column).

Table 2: Statistical analysis of the N400 effect

\begin{tabular}{|c|c|c|c|c|c|c|}
\hline \multirow[b]{2}{*}{ Electrode(s) } & \multicolumn{2}{|c|}{ RJT } & \multicolumn{2}{|c|}{ SJT } & \multicolumn{2}{|c|}{ GJT } \\
\hline & controls & dyslexics & controls & dyslexics & controls & Dyslexics \\
\hline \multirow[t]{2}{*}{ Midline } & 50.01 & 44.03 & 26.21 & $1 \mathrm{I} .74$ & 18.15 & 7.59 \\
\hline & $\mathrm{P}<.0000 \mathrm{I}$ & $\mathrm{p}=.0001$ & $p=.0005$ & $P=.0065$ & $p=.0017$ & $\mathrm{p}=.0203$ \\
\hline \multirow[t]{2}{*}{ parasagittal } & 32.54 & 27.39 & 20.93 & 9.02 & 29.79 & 10.2 \\
\hline & $P=.0002$ & $P=.0004$ & $p=.001$ & $P=.0133$ & $P=.0003$ & $P=.0096$ \\
\hline \multirow[t]{2}{*}{ temporal } & 13.76 & 5.04 & 7.69 & 5.02 & 21.88 & 11.86 \\
\hline & $P=.0040$ & $P=.0487$ & $P=.0197$ & $P=.049$ & $p=.0009$ & $P=.0063$ \\
\hline \multirow[t]{3}{*}{ C4 } & 55.04 & 48.99 & 29.02 & 8.91 & 21.34 & 14.06 \\
\hline & $\mathrm{P}<.0000 \mathrm{I}$ & $P=.0002$ & $\mathrm{p}=.0003$ & $\mathrm{p}=.0137$ & $\mathrm{P}=.001$ & $\mathrm{p}=.0038$ \\
\hline & $6.16 \mu \mathrm{V}$ vs. $2.25 \mu \mathrm{V}$ & $3.12 \mu \mathrm{V}$ vs. $0.14 \mu \mathrm{V}$ & $3.32 \mu \mathrm{V}$ vs. $-\mathrm{I} .25 \mu \mathrm{V}$ & $2.86 \mu \mathrm{V}$ vs. $-2.22 \mu \mathrm{V}$ & $5.64 \mu \mathrm{V}$ vs. $2.99 \mu \mathrm{V}$ & $3.29 \mu \mathrm{V}$ vs. I. $46 \mu \mathrm{V}$ \\
\hline
\end{tabular}

Statistical evaluation of the N400 (RJT, SJT) and the anterior negativity (GJT). The F(I, I0)- and p-values for the main effect of WORD TYPE (congruent vs. incongruent) are shown for the different electrode clusters used (see text). As a further illustration, the results for the single electrode C4 are also shown. Note that in all analyses except for the midline electrodes, the WORD TYPE by ELECTRODE interactions were significant (all $p<.05$ ). Mean amplitudes in the following time-windows were used: RJT: $250-600 \mathrm{~ms}$; SJT: $250-600 \mathrm{~ms} ; \mathrm{GJT}: 450-700 \mathrm{~ms}$. 

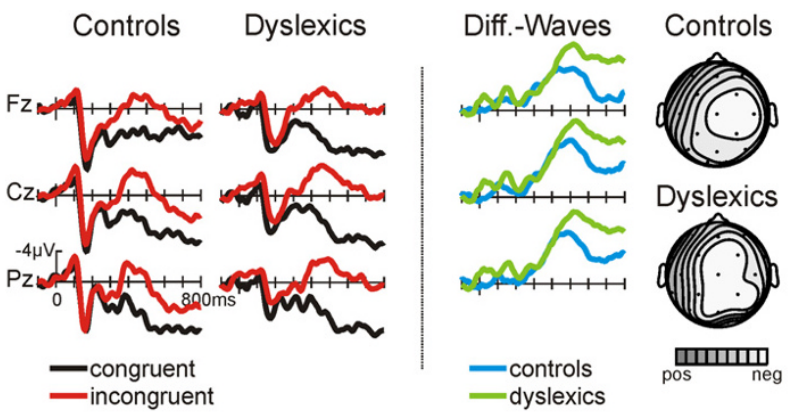

Figure 2

ERPs in the SJT. ERPs in the semantic judgment task for the control groups (left) and for dyslexic readers (middle). The right column depicts the difference waves (incongruent congruent) for the control group (solid line) and for the dyslexic readers (dotted line). Voltage and time scales of the left column pertain to all columns. Distributions are illustrated for the maximum of the difference waves as spline-interpolated isovoltage maps (relative scaling, controls $\mathrm{min} / \mathrm{max}-6.3$ / $-0.3 \mu \mathrm{V}$, dyslexics $-8.2 / 2.2 \mu \mathrm{V}$ ).

The difference waves (incorrect - correct, figure 3, third column) show an anterior negativity which starts earlier in normal compared to dyslexic readers. This is reflected by onset latency differences between the two groups (onesided t-test against 0: control $440 \mathrm{~ms}$, dyslexics: $504 \mathrm{~ms}$; measured at electrode C4). Due to the differences in onset latency of the anterior negativity, peak amplitude for each subject was determined in a time-window ranging from 200 to $700 \mathrm{~ms}$ to evaluate amplitude differences between
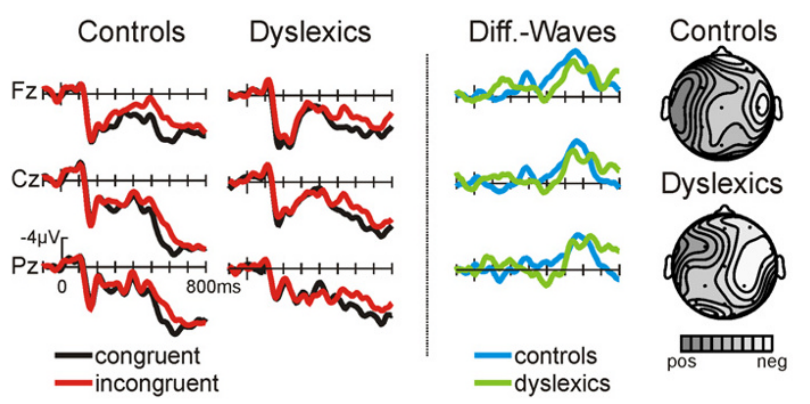

Figure 3

ERPs in the GJT. ERPs in the syntactic judgment task for the control groups (left) and for dyslexic readers (middle). The right column depicts the difference waves (incongruent congruent) for the control group (solid line) and for the dyslexic readers (dotted line). Voltage and time scales of the left column pertain to all columns. Distributions are illustrated for the maximum of the difference waves as spline-interpolated isovoltage maps (relative scaling, controls $\mathrm{min} / \mathrm{max}-3.9$ / $-\mathrm{I} .0 \mu \mathrm{V}$, dyslexics $-3.2 / 0.3 \mu \mathrm{V}$ ). the groups. Despite the impression of a slightly larger peak amplitude for the control group, the ANOVAs did not show any significant main effect of GROUP or a significant interaction between the GROUP and the electrodes factors. The incongruency effect (larger anterior negativity amplitude for syntactically incorrect words compared to syntactically correct words) turned out to be highly significant for both groups (see Table 2 ).

\section{Comparison between the three tasks}

Figure 4 shows the difference waves of the three tasks for the control group and dyslexic readers. It can be seen that the onset of the difference waves in normal readers does not differ for the semantic and rhyme judgment tasks whereas the anterior negativity for the syntactic judgment task has a later onset latency (controls: RJT: $240 \mathrm{~ms}$; SJT: $272 \mathrm{~ms}$; GJT: $440 \mathrm{~ms}$ as determined by serial t-tests at electrode $\mathrm{C} 4$ ). For dyslexic readers, the same pattern emerged, but the incongruency effect for the RJT begins later than for the control group (dyslexics: SJT: $272 \mathrm{~ms}$; RJT: $272 \mathrm{~ms}$; GJT: $504 \mathrm{~ms}$ ).

The topographies of the incongruency effects can be appreciated from the maps presented in figures 1 to 3 . The topographies for rhyme and semantic tasks are very similar. In contrast, the anterior negativity in the GJT shows a
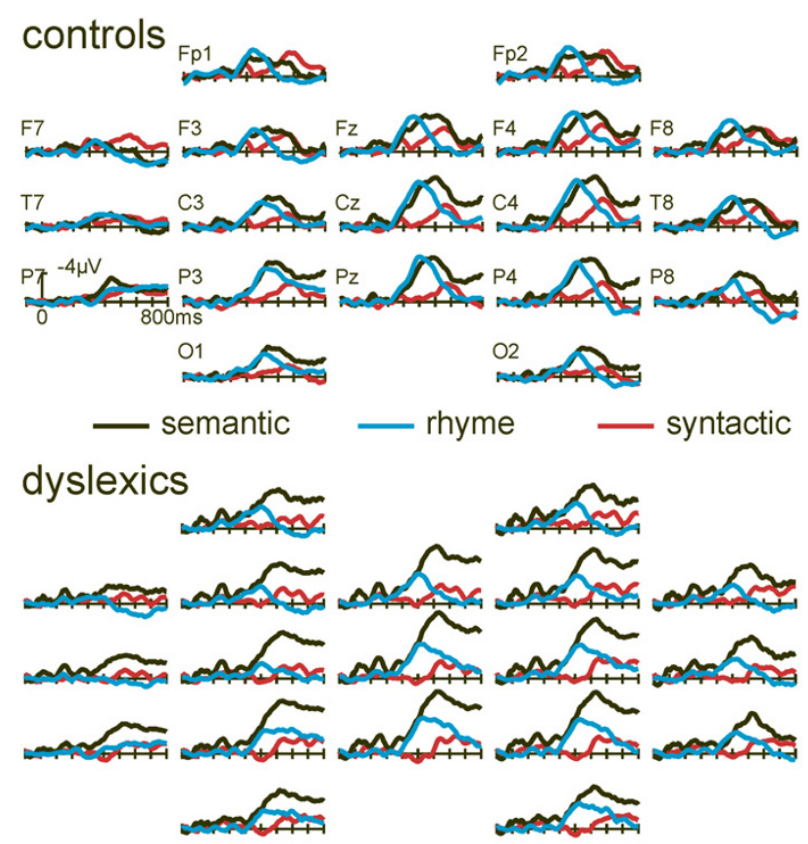

Figure 4

Difference ERPs for the three tasks. Difference potentials (incongruent - congruent) for all three tasks for the control group (top) and dyslexic readers (bottom). Note the different onset latencies in the $\mathrm{N} 400$ and the anterior negativity both within and across groups. 
more frontal distribution for both groups. Distributions are very similar for both groups. Statistically, this is reflected in non-significant GROUP (dyslexics, control) by ELECTRODE (29) interactions in ANOVAs of the standardized mean amplitudes in the N400/anterior negativity time-windows (RTT: $380-440 \mathrm{~ms}$; SJT: $480-540$ ms; GJT: peak GJT: peak amplitude; all F's < 1). Furthermore, in ANOVAs of the standardized data comprising the repeated measures factors TASK (RTT, SJT, GJT) and ELECTRODE (29), significant interactions emerged for TASK and ELECTRODE (controls: $\mathrm{F}(2,56)=15.61, \mathrm{p}<.0001$; dyslexics: $F(2,56)=7.74, p<.002$ ). Post-hoc comparisons revealed that the GJT-anterior negativity topography differs from both, the SJT and the RJT topography of the N400 in dyslexics as well as controls. No differences were seen between SJT and RJT.

\section{Discussion}

The present study employed phonological, semantic, and syntactic judgment tasks to investigate the processing of visually presented words in adult dyslexic and normal readers with event-related brain potentials. Normal readers responded faster compared to dyslexics in all three tasks. Furthermore, both, dyslexic as well as normal readers were faster in their responses in the rhyme judgment compared to the other two tasks. In all three tasks the incongruent words were characterized by more negative going ERPs of different distributions. The onset latencies of these negative effects were delayed in dyslexic readers compared to controls in the phonological judgment and in the gender judgment task, but not in the semantic judgment task. Peak amplitudes did not differ between the two groups. In the phonological judgment and the semantic judgment tasks the incongruency effects persisted longer in the dyslexic groups. While some authors $[72,73]$ have pointed out that the phonological and semantic effects have different distributions, we will use the label N400 for both, the semantic and phonological incongruency effects, while the syntactic effect will be termed anterior negativity.

The phonological N400 displayed a delayed onset and persisted longer in our sample of adult dyslexic readers. This indicates that adult dyslexics have difficulties with phonological processing of written words, a finding that is compatible with the notion of a phonological core deficit in developmental dyslexia $[6,74,75]$. In line with previous research [64-66], we observed a normal N400 semantic priming effect in adult dyslexic readers: $\mathrm{N} 400$ onset latency was not delayed for dyslexics in the semantic judgment task, and N400 peak amplitude was comparable in impaired and normal readers. As was the case with the phonological task, the semantic N400 persisted longer in dylexics. Furthermore, they needed longer to perform the semantic judgment task. Thus, it seems that dyslexic read- ers need more time and effort for semantic integration processes. Similar results were obtained in a sentence reading task using slow presentation rates comparable to the ones used here ( $600 \mathrm{~ms}$ SOA in the present study, 700 ms SOA in [63]).

With regard to syntactic processing, we observed a delayed onset and a longer persistence of the anterior negativity as well as prolonged response times indicating syntactic processing difficulties in dyslexic adults. Interestingly, in an auditory sentence comprehension task in dyslexic children [70] a delayed anterior negativity was observed as well. Moreover, in this study normal readers showed a bilateral distribution of the negativity (suggesting a contribution of prosodic right hemisphere processes), while the strong left lateralization in the dyslexics suggested no contribution of prosodic/phonological processes in the detection of the phrase structure violations. This pattern might be taken to suggest an impairment of phonological processing which results in problems of automatic syntactic processing. Our own data lend themselves to similar interpretation.

To summarize, the present experiment suggest that adult dyslexic readers do not only show phonological difficulties in written word processing but also have problems in syntactic and semantic integration processes. Remediation programs created for dyslexic adult readers should take these processing deficits into account.

\section{Conclusion}

The present study replicates the well-known finding that dyslexics are phonologically impaired (delayed N400 in the rhyme judgment task). Furthermore, we show that they also have difficulties in other, non-phonological aspects of reading (longer response times, longer persistence of the N400). Specifically, semantic and syntactic integration seem to require more effort for dyslexic readers and take longer irrespective of the reading task that has to be performed. These aspects of reading impairment in dyslexia should be taken into account when designing new interventions for dyslexic readers.

\section{Methods \\ Subjects}

Developmental dyslexics were selected from 102 adults with self-reported reading and spelling difficulties who responded to a newspaper advertisement. Out of this collective, all adults above the age of 18 and below 40 with a high-school degree (or attending the final high-school class) were invited for neuropsychological testing, which included full-scale IQ testing by the German version of the WAIS-R (HAWIE-R, [76], a standardized test of spelling skill (R-T; dictation c: Moselfahrt, [77]) and a self-constructed dictation task consisting of 253 German words. 
Dyslexia was defined as a deficit in spelling ability as assessed with the R-T (at least $1.5 \mathrm{~s}$.d. below the error rate expected from individual IQ) and a minimum of 60 misspellings in the self-constructed dictation task. Furthermore, a self-constructed computerized reading test ("Readspeed") indicated that dyslexic participants had a slower reading speed (silent reading, normal readers: mean 463 ms per word (s.d. $29 \mathrm{~ms}$ ), dyslexic readers: 918 $\mathrm{ms}(122 \mathrm{~ms}), \mathrm{T}(22)=3.78, \mathrm{p}<.01$; reading aloud, normal readers: $612 \mathrm{~ms}(58 \mathrm{~ms})$, dyslexic readers: $988 \mathrm{~ms}(109$ $\mathrm{ms}), \mathrm{T}(22)=3.12, \mathrm{p}<.01)$. In this test, subjects have to read a short story word by word either aloud or silent, and the response time to each word is measured. Only participants with an IQ of at least 110 were included in the study. All participants were native speakers of German. Exclusion criteria included poor educational opportunities, neurological disease or seizures, a self-reported history of attention-deficit hyperactivity disorder (ADHD) and auditory or visual impairments that might have interfered with reading skill acquisition. Eleven dyslexic subjects were recruited for participation (mean age: 24.9 yrs, range 19-30, 1 left-handed according to self-report, 1 woman). The 11 control subjects had a mean age of 26.1 yrs. (range 19-33, 2 left-handed, 1 woman) and were students at Hannover Medical School. There were no reliable differences in age, sex or handedness between dyslexics and controls. Mean IQ differed slightly between the two samples (controls: 135, range: 118-150, dyslexics: 126, range: $111-136 ; \mathrm{T}(20)=2.598, \mathrm{p}<.0172)$. On average, control subjects had completed 16.3 yrs. of education compared to of $16.5 \mathrm{yrs}$ for the dyslexics $(\mathrm{T}(20)<1)$. Controls and dyslexics differed with respect to their spelling ability (R-T: 7.3 vs. 27.4 errors, $\mathrm{T}(20)=7.7, \mathrm{p}<.0001$; dictation test: 19.8 vs. 98 errors, $\mathrm{T}(20)=11.86, \mathrm{p}<.0001$ ). All participants received monetary compensation and gave informed consent to their participation. The study was approved by the ethics committees of Hannover Medical School and of the University of Magdeburg.

\section{Stimuli and procedure}

Subjects participated in three different tasks that were conducted on different days in random order. On each day, several other ERP-paradigms were administered in addition (for details, see $[33,34,66,78]$. Each task comprised the subsequent presentation of two words on a computer screen. Each trial started with a fixation cross appearing for $500 \mathrm{~ms}$ in the center of the screen. The first word was then displayed for $200 \mathrm{~ms}$ and replaced by the fixation cross. Six hundred ms after the offset of the first word the second word was shown for $200 \mathrm{~ms}$. The inter-trial interval (time from offset of the second word of a trial to the onset of the first word of the following trial) was randomly varied between $3000 \mathrm{~ms}$ and $4500 \mathrm{~ms}$. Word length ranged from 3 to 12 letters. All words were written in yellow capital letters $(1.5 \times 0.9 \mathrm{~cm})$ on a dark blue background and were viewed from a constant viewing distance of $90 \mathrm{~cm}$. Response-times were measured from target-onset to response execution.

For the rhyme-judgment task (RJT), 240 word pairs (German nouns) that constitute a rhyme (e.g. Haus - Maus [house - mouse]) and 240 non-rhyme word pairs (e.g. Bett - Kind [bed - child]) were presented. Subjects had to indicate with a button press whether the two words constituted a rhyme or not. For the semantic judgment task (SJT), 240 semantically related (e.g. Gabel - Messer [fork - knife]) and 240 semantically unrelated word pairs (e.g. Blatt - Stern; [leave - star]) were constructed. Subjects had to indicate whether the two words were semantically related or not. In the third task 240 word pairs consisting of a definite article and a noun agreeing with respect to gender (der Hut [the hat; masculine gender]) and 240 additional word pairs with incorrect gender matching (das Chemie [the chemistry; neutral gender, correct gender in German is feminine]) were used. Participants had to indicate whether the word pair was grammatically correct or not (thus GJT = grammatical judgment task). Different words were used for all three conditions. Word frequency for the critical second words of the pairs ranged from 1 to 6413 occurences per 1 million words (Celex database [79]) and did not differ for the three tasks (RJT: mean frequency 220 occurences per 1 million words, SJT: 296, GJT: 226; $F(2,238)<1)$. In all three tasks, the wordpairs were presented in random order. A response button was positioned beneath each thumb. In each of the tasks, for six dyslexic as well as for six normal readers, the right button was used to signal a "yes" response and the left button was assigned to the "no" response. For the remaining subjects the order was reversed.

Importantly, for all three tasks different lists were created such that a given word appeared in the matching and nonmatching conditions with equal probability. For example, in the semantic judgment task, in one scenario/HAUS/ (house) served as the prime for an unrelated target like/ AUTO/(car), in the second scenario it served as a prime for a related target/GEBÄUDE/(building), in the third it served as the target to an unrelated prime, and in the fourth scenario it served as the target to a related prime. Similar lists were constructed for the syntactic and rhyme judgment tasks. The choice of the actual scenario presented was counterbalanced across subjects.

\section{ERP-recording and data analysis}

Subjects were seated in a comfortable chair placed in a sound attenuated and electrically shielded room and were instructed to relax. The EEG was recorded with tin electrodes mounted in an elastic cap (Electro Cap International, Eaton, OH) from 29 sites placed according to the International 10/20 system [80] referenced to an electrode 
located on the right mastoid. Horizontal eye movements were monitored with a bipolar montage using electrodes located on the outer ocular canthi of the left and right eye. Vertical eye movements were detected through electrodes located below and above the right eye. All channels were amplified using a 10 second time constant and processed with a bandpass filter between 0.01 and $100 \mathrm{~Hz}$ (half amplitude low and high frequency cut-offs), digitized at a rate of $250 \mathrm{~Hz}$ (AD resolution $12 \mathrm{Bit}, 4 \mathrm{~ms}$ ) and stored on a harddisk. Trials with eye-movement or blink artifacts were rejected using individualized amplitude criteria on the eye-channels by a computer routine. Briefly, a number of representative blinks of the particular subject were inspected and the rejection criteria were set such that blink artifacts were reliably rejected. In addition, routines for the detection of amplifier blocking were included.

ERPs were averaged separately for each subject, task, congruent, and incongruent target words for a time period of $1000 \mathrm{~ms}$ relative to a $100 \mathrm{~ms}$ prestimulus baseline. Only artifact-free trials with a correct response in the time-window $200 \mathrm{~ms}$ to $2500 \mathrm{~ms}$ after prime-onset were used for this procedure. Group averages were created by averaging the ERPs of all dyslexic and normal readers, respectively.

Difference potentials were computed for each task by subtracting point by point the potential evoked by congruent targets from that evoked by incongruent target words. These difference potentials reflect the neural correlates of semantic, phonological, and syntactic incongruency.

The data were evaluated using repeated measures analyses of variance (ANOVA) of the differences waves (incongruent - congruent condition). Factors used in the ANOVA were GROUP (dyslexic readers vs. normal readers; between subjects factor) as well as electrode factors as within subjects factors. Separate analyses were done for the midline (ML: Fz, Cz, Pz), parasagittal (PS: Fp1/2, F3/ 4, C3/4, P3/4, O1/2) and temporal (TE: F7/8, T3/4, T5/6) electrodes. In the ML analysis the electrodes yielded the three levels of an ANTERIORITY factor, while for the latter two sets electrodes were entered to yield an ANTERIORITY (PS: 5 levels, TE: 3 levels) and a LATERALITY (levels: left, right) factor. Arranging different analyses for the various electrode sets was preferred to including all sites into a single factor, since this option has less descriptive value regarding the topography of ERP-effects. Furthermore, to show the significance of the congruency effect proper, ANOVAs with the factors WORD TYPE (congruent, incongruent) and the electrode factors were computed separately for each task and for dyslexic as well as normal readers.

To assess topographical differences in the obtained ERPeffects between the RJT, SJT, GJT, and dyslexic and normal readers, we first performed the standardization of the data proposed by [81]. This is necessary because of non-linearity of signal conduction in the brain tissue and in the skull, ANOVA-models may confuse differences in the amplitude of an EEG-signal (due to differences in source strength) with genuine topographic differences. These standardized data were submitted to various ANOVAs. In all ANOVAs, the correction for non-spericity with the Huyhn-Feldt-epsilon coefficient was performed whenever applicable. Reported p-values are corrected.

N400 onset latencies and the onset latency of the anterior negativity in the GJT were computed by conducting onesample t-tests against 0 for the difference waves for each group and each task. These were computed in the timerange 100 to $700 \mathrm{~ms}$ after stimulus presentation. Moving time-windows of $40 \mathrm{~ms}$ length were employed (i.e. the first time-window ranged from 100 to $140 \mathrm{~ms}$, the second from 108 to $148 \mathrm{~ms}$ and so on). The middle point of the first time-window with a significant difference from 0 was taken as the onset latency, but only when at least three consecutive time-windows yielded a significant result. Furthermore, N400 onset latencies were computed and statistically evaluated with the jackknife-method as described by [82]. Here, a criterion of $20 \%$ of the maximum amplitude was used for determination of the onset and the differences waves were filtered (low-pass $8 \mathrm{~Hz}$ ) prior to conducting the jackknife procedure. As these analyses yielded a virtually identical pattern to the approach described above, they will not be reported in detail in the results section.

\section{Abbreviations}

ERP: event-related potential

RJT: rhyme judgment task

SJT: semantic judgment task

GJT: gender judgment task

RT: Reaction time

ANOVA: analysis of variance

WAIS-R: Wechsler Adult Intelligence Scale - Revised

HAWIE-R: Hamburg-Wechsler Intelligenztest für Erwachsene

R-T: Rechtschreibtest

\section{Authors' contributions}

JR, SJ and TFM designed the study. PB acquired the data. JR analyzed the data. JR and TFM drafted the manuscript. 


\section{Acknowledgements}

We thank Justyna Kowalczuk, Stefan Probst and Florian Bewers for help in subject selection and data acquisition and Jobst Kilian for technical support.

Financial support for this study was obtained from the German Research Foundation (Deutsche Forschungsgemeinschaft, DFG; RU846/I-I, RU846/ I-2).

\section{References}

I. Dilling $\mathrm{H}$, Mombour W, Schmidt $\mathrm{MH}$ : International Classification of metal diseases ICD-10. Bern, Huber; 1991.

2. Shaywitz SE, Shaywitz BA: Dyslexia (specific reading disability). Biol Psychiatry 2005, 57:1301-I309.

3. Esser G: Was wird aus Kindern mit Teilleistungsschwächen? Der langfristige Verlauf umschriebener Entwicklungsstörungen Stuttgart: Ferdinand Enke; 1991.

4. Katusic SK, Colligan RC, Barbaresi WJ, Schaid DJ, Jacobsen SJ: Incidence of reading disability in a population-based birth cohort, 1976-1982, Rochester, Minn. Mayo Clin Proc 2001, 76(I I): $1081-92$

5. Remschmidt H, Walter R: Evaluation Kinder- und Jugendpsychiatrischer Versorgung. Analysen und Erhebungen in drei hessischen Landkreisen Stuttgart: Enke; 1989.

6. Shaywitz SE: Dyslexia. N Engl J Med 1998, 338:307-3I2.

7. Bruck M: Word recognition skills of adults with childhood diagnoses of dyslexia. Dev Psychol 1990, 26:439-454.

8. Francis DJ, Shaywitz SE, Stuebing KK, Shaywitz BA, Fletcher JM: Developmental lag versus deficit models of reading disability: a longitudinal, individual growth curve analysis. J Educ Psychol 1996, 88:3-17.

9. Shaywitz BA, Holford TR, Holahan JM, Fletcher JM, Stuebing KK, Francis DJ, et al.: A Matthew effect for IQ but not for reading: results from a longitudinal study. Reading Research Quarterly 1995, 30:894-906.

10. Felton RH, Naylor CE, Wood FB: Neuropsychological profile of adult dyslexics. Brain Lang 1990, 39:485-497.

II. Miller-Shaul S: The characteristics of young and adult dyslexics readers on reading and reading related cognitive tasks compared to normal readers. Dyslexia 2005, I I:|32-|5|

12. Rüsseler J, Sambale C, Wildner J, Müller SV, van der Lugt A, Münte TF: Event-related brain potentials to sound omissions in adult normal and dyslexic readers Edited by: Tobias HD. Focus on Dyslexia Research. Hauppage, NY: Nova Science Publishers; 2004: I 5 I-I7I.

13. Scarborough HS: Very early language deficits in dyslexic children. Child Dev 1990, 61:1728-1743.

14. Fisher SE, DeFries JC: Developmental dyslexia: genetic dissection of a complex cognitive trait. Nat Rev Neurosci 2002, 3:767-780

15. Galaburda AM, LoTurco J, Ramus F, Fitch RH, Rosen GD: From genes to behaviour in developmental dyslexia. Nat Neurosci 2006, 9:1213-1217.

16. Grigorenko EL: Developmental dyslexia: An update on genes, brains and environments. I Child Psychol Psychiatry 200I, 42:9I-I25.

17. McGrath LM, Smith SD, Pennington BF: Breakthroughs in the search for dyslexia candidate genes. Trends Mol Med 2006, | 2:333-341.

18. Demonet JF, Taylor MJ, Chaix Y: Developmental dyslexia. Lancet 2004, 363:|45|-|460.

19. Schumacher J, Anthoni H, Dahdouh F, et al.: Strong genetic evidence of DCDC2 as a susceptibility gene for dyslexia. Am J Hum Genet 2006, 78:52-62.

20. Livingstone MS, Rosen GD, Drislane FW, Galaburda AM: Physiological and anatomical evidence for a magnocellular deficit in developmental dyslexia. Proc Natl Acad Sci USA 1991, 88:7943-7947.

21. Tallal P: Auditory temporal perception, phonics, and reading disabilities in children. Brain Lang 1980, 9:182-198.

22. Tallal P: The science of literacy: from the laboratory to the classroom. Proc Natl Acad Sci USA 2000, 97:2402-2404.

23. Tallal P, Miller S, Fitch R: Neurobiological basis of speech: A case for the preeminence of temporal processing. Ann NY Acad Sci 1993, 682:27-47.
24. Nicolson RI, Fawcett AJ, Dean P: Developmental dyslexia: the cerebellar deficit hypothesis. Trends Neurosci 200I, 24:508-5I I.

25. Stein J: The magnocellular theory of developmental dyslexia. Dyslexia 200I, 7:12-36.

26. Liberman IY, Shankweiler D, Liberman AM: Phonology and reading disability: solving the reading puzzle Edited by: Shankweiler D, Liberman IY. International Academy for Research in Learning Disabilities monograph series, Ann Arbor, Mi.: University of Michigan Press; 1989:1-33.

27. Beaton AA: Dyslexia, reading, and the brain. A sourcebook of psychological and biological research Hove: Psychology Press; 2004.

28. Eckert M: Neuroanatomical markers for dyslexia: a review of dyslexia structural imaging studies. Neuroscientist 2004, I 0:362-37I.

29. Ramus F: Developmental dyslexia: specific phonological deficit or general sensorimotor dysfunction? Curr Opin Neurobiol 2003, 13:212-218.

30. Bonte ML, Poelmans H, Blomert L: Deviant neurophysiological responses to phonological regularities in speech in dyslexic children. Neuropsychologia 2007, 45: |427-I437.

3I. Johannes S, Kussmaul CL, Munte TF, Mangun GR: Developmental dyslexia: passive visual stimulation provides no evidence for a magnocellular processing deficit. Neuropsychologia 1996, 34:1123-1127.

32. Moisescu-Yiflach T, Pratt $\mathrm{H}$ : Auditory event-related potentials and source current density estimation in phonologic/auditory dyslexics. Clin Neurophysiol 2005, I 1 6:2632-2647.

33. Rüsseler J, Kowalczuk J, Johannes S, Wieringa BM, Münte TF: Cognitive brain potentials to novel acoustic stimuli in adult dyslexic readers. Dyslexia 2002, 8: | 25- 142

34. Rüsseler J, Johannes S, Kowalczuk J, Wieringa BM, Münte TF: Developmental dyslexics show altered allocation of attention in visual classification tasks. Acta Neurol Scand 2003, 107:22-30.

35. Schulte-Körne G, Deimel W, Bartling J, Remschmidt H: Auditory processing and dyslexia: evidence for a specific speech processing deficit. Neuroreport 1998, 9:3355-3358.

36. Schulte-Körne G, Deimel W, Bartling J, Remschmidt H: Pre-attentive processing of auditory patterns in dyslexic human subjects. Neurosci Lett 1999, 276:41-44.

37. Schulte-Körne G, Deimel W, Bartling J, Remschmidt H: Speech perception deficit in dyslexic adults as measured by mismatch negativity (MMN). Int J Psychophysiol 200I, 40:77-87.

38. Connolly JF, D'Arcy RC, Lynn Newman R, Kemps R: The application of cognitive event-related brain potentials (ERPs) in language-impaired individuals: review and case studies. Int J Psychophysiol 2000, 38:55-70.

39. Heim S, Keil A: Large-scale neural correlates of developmental dyslexia. Eur Child Adolesc Psychiatry 2004, I 3:125-140.

40. Kujala T, Näätänen R: The mismatch negativity in evaluating central auditory dysfunction in dyslexia. Neurosci Biobehav Rev 200I, 25:535-543.

4l. Hagoort P, Brown C, Osterhout L: The neurocognition of syntactic processing Edited by: Brown CM, Hagoort P. Neurocognition of Language, Oxford: Oxford University Press; 1999:273-317.

42. Kutas M, Federmeier KD: Electrophysiology reveals semantic memory use in language comprehension. Trends Cogn Sci 2000, 4:463-470.

43. Kutas M, Hillyard SJ: Reading senseless sentences: brain potentials reflect semantic anomaly. Science 1980, 207:203-205.

44. Brown C, Hagoort P: The processing nature of the N400: evidence from masked priming. J Cogn Neurosci 1993, 5:34-44.

45. Hagoort P: How the brain solves the binding problem for language: a neurocomputational model of syntactic processing. Neuroimage 2003, 20(SuppI I):SI8-29.

46. Kutas M, van Petten CK: Psycholinguistics electrified: event-related brain potential investigations Edited by: Gernsbacher MA. Handbook of Psycholinguistics, San Diego: Academic Press; 1994:83-143.

47. Osterhout L, Holcomb PJ: Event-related brain potentials elicited by syntactic anomaly. J Mem Lang 1992, 3 I:785-806.

48. Osterhout L, Holcomb PJ: Event-related potentials and language comprehension Edited by: Rugg MD, Coles MGH. Electrophysiology of Mind, Oxford: Oxford University Press; 1995: I7I-2I5.

49. Praamstra P, Stegeman DF: Phonological effects on the auditory N400 event-related brain potential. Brain Res Cogn Brain Res 1993, I:73-86.

50. Praamstra P, Meyer AS, Levelt JM: Neurophysiological manifestations of phonological processing: Latency variation of a neg- 
ative ERP component time-locked to phonological mismatch. J Cogn Neurosci 1994, 6:204-219.

51. Rugg MD, Barrett SE: Event-related potentials and the interaction between orthographic and phonological information in a rhyme judgment task. Brain Lang 1987, 32:336-36I.

52. Rugg MD: Event-related potentials in phonological matching tasks. Brain Lang 1984, 23:225-240.

53. Rugg MD: Event-related potentials in the phonological processing of words and non-words. Neuropsychologia 1984, 22:435-443

54. Haan H, Streb J, Bien S, Rösler F: Individual cortical current density reconstructions of the semantic $\mathrm{N} 400$ effect: using a generalized minimum norm model with different constraints (LI and L2 norm). Hum Brain Mapp 2000, I I: I78-192.

55. Münte TF, Heinze H-J, Mangun GR: Dissociation of brain activity related to syntactic and semantic aspects of language. J Cogn Neurosci 1993, 5:335-344.

56. Rösler F, Friederici A, Pütz P, Hahne A: Event-related potentials while encountering semantic and syntactic constraint violations. J Cogn Neurosci 1993, 5:345-362.

57. Friederici $A D$, Hahne $A$, Mecklinger $A$ : Temporal structure of syntactic parsing: early and late event-related brain potential effects. I Exp Psychol: Learn Mem Cogn 1996, 22:1219-1248.

58. Johannes S, Mangun GR, Kussmaul CL, Münte TF: Brain potentials in developmental dyslexia: differential effects of word frequency in human subjects. Neurosci Lett 1995, 195:183-186.

59. Stelmack RM, Miles J: The effect of picture priming on eventrelated potentials of normal and disabled readers during a word recognition memory task. J Clin Exp Neuropsychol 1990, 1 2:887-903.

60. Stelmack RM, Saxe BJ, Noldy-Cullum N, Campbell KB, Armitage R: Recognition memory for words and event-related potentials: a comparison of normal and dyslexic readers. J Clin Exp Neuropsychol 1988, 10:185-200.

6I. McPherson WB, Ackerman PT, Holcomb PJ, Dykman RA: Eventrelated brain potentials elicited during phonological processing differentiate subgroups of reading disabled adolescents. Brain Lang 1998, 62:163-185.

62. McPherson WB, Ackerman PT, Oglesby DM, Dykman RA: Eventrelated brain potentials elicited by rhyming and non-rhyming pictures differentiate subgroups of reading disabled adolescents. Integr Physiol Behav Sci 1996, 31:3-17.

63. Robichon F, Besson M, Habib M: An electrophysiological study of dyslexic and control adults in a sentence reading task. Biol Psychol 2002, 59:29-53.

64. Bonte ML, Blomert L: Developmental dyslexia: ERP correlates of anomalous phonological processing during spoken word recognition. Brain Res Cogn Brain Res 2004, 21:360-376.

65. Silva-Pereyra J, Rivera-Gaxiola M, Fernandez T, et al.: Are poor readers semantically challenged? An event-related brain potential assessment. Int J Psychophysiol 2003, 49: I87-I99.

66. Rüsseler J, Probst S, Johannes S, Münte TF: Recognition memory for high- and low-frequency words in adult normal and dyslexic readers: an event-related brain potential study. J Clin Exp Neuropsychol 2003, 25:815-829.

67. Leikin M: Processing syntactic functions of words in normal and dyslexic readers. J Psycholinguistic Res 2002, 31:|45-163.

68. Rispens J: Syntactic and phonological processing in developmental dyslexia Volume 48. University of Groningen: Groningen Dissertations in Linguistics; 2004. ISSN 0928-0030

69. Hahne A, Friederici AD: Electrophysiological evidence for two steps in syntactic analysis. Early automatic and late controlled processes. J Cogn Neurosci 1999, I I: 194-205.

70. Sabisch B, Hahne A, Glass E, von Suchodoletz W, Friederici AD: Auditory language comprehension in children with developmental dyslexia: evidence from event-related brain potentials. J Cogn Neurosci 2006, 18:1676-1695.

7I. Ramus F, Rosen S, Dakin SC, Day BL, Castellote JM, White S, Frith U: Theories of developmental dyslexia: insights from a multiple case study of dyslexic adults. Brain 2003, 126:84|-865.

72. Diaz MT, Swaab TY: Electrophysiological differentiation of phonological and semantic integration in word and sentence contexts. Brain Res 2007, I I 46:85-100.

73. Newman RL, Conolly JF: Determining the role of phonology in silent reading using event-related brain potentials. Brain Res Cogn Brain Res 2004, 21 :94-105.
74. Goswami U, Bryant P: Phonological skills and learning to read Hove: Lawrence Erlbaum Associates; 1990.

75. Griffiths YM, Snowling M: Predictors of exception eord and nonword reading in dyslexic children: The severity hypothesis. Educ Psychol 2002, 94:34-43.

76. Tewes U: Hamburg-Wechsler Intelligenztest für Erwachsene. Revision 199I Bern: Verlag Hans Huber; 1991.

77. Deutsche Gesellschaft für Personalwesen: Rechtschreibtest (R-T) Göttingen: Hogrefe; 1974.

78. Rüsseler J, Johannes S, Münte TF: Recognition memory for unfamiliar faces does not differ for adult normal and dyslexic readers: an event-related brain potential study. Clin Neurophysiol 2003, I | 4: |285-I29|.

79. Baayen RH, Piepenbrock R, Gulikers L: The CELEX Lexical Database (Release 2) [CD-ROM] Philadelphia: PA: Linguistic Data Consortium, University of Pennsylvania [Distributor]; 1995.

80. Jasper $\mathrm{HH}$ : The ten-twenty electrode system of the international federation. Electroencephalogr Clin Neurophysiol 1958, 20:37I-375

8I. McCarthy G, Wood C: Scalp distribution of event-related potentials: an ambiguity associated with analysis of variance models. Electroencephalogr Clin Neurophysiol 1985, 62:203-208.

82. Miller J, Patterson T, Ulrich R: Jackknife-based method for measuring LRP onset latency differences. Psychophysiology 1998, 35:99-II5.

Publish with Bio Med Central and every scientist can read your work free of charge

"BioMed Central will be the most significant development for disseminating the results of biomedical research in our lifetime. "

Sir Paul Nurse, Cancer Research UK

Your research papers will be:

- available free of charge to the entire biomedical community

- peer reviewed and published immediately upon acceptance

- cited in PubMed and archived on PubMed Central

- yours - you keep the copyright
BioMedcentral 